NÉCROLOGIE

\title{
DÉCÈS D'YVONNE HENTSCH
}

Mademoiselle Yvonne Hentsch, ancienne sous-secrétaire générale de la Ligue des Sociétés de la Croix-Rouge, nous a quittés le 4 mai 1991 à Genève, à l'âge de 84 ans. Avec elle disparaît une grande figure de la CroixRouge et des soins infirmiers.

Diplômée de l'Ecole d'infirmières «La Source» à Lausanne (Suisse), la plus ancienne école d'infirmières indépendante du monde (fondée en 1859), Yvonne Hentsch a commencé sa carrière professionnelle dans une maternité à Bari, dans le sud de l'Italie, avant de poursuivre des études supérieures au Bedford College de l'Université de Londres, au Royal College of Nursing à Londres et au Teachers' College de l'Université de Columbia à New York.

Sa carrière internationale a débuté à la Ligue des Sociétés de la CroixRouge en 1939; elle y fut directrice du Bureau des infirmières pendant plus de 30 ans avant d'être nommée en 1972 sous-secrétaire générale chargée du secteur des services aux Sociétés nationales, poste qu'elle occupa jusqu'à sa retraite.

$M^{\text {Ile }}$ Hentsch a maintenu des contacts étroits avec le CICR, le Conseil international des infirmières, l'Organisation mondiale de la Santé et surtout les Sociétés nationales de la Croix-Rouge et du Croissant-Rouge ainsi qu'avec les associations nationales et régionales d'infirmières dans le monde entier; elle a accompli ainsi des missions auprès de quelque 80 Sociétés nationales et pris part à de nombreuses conférences internationales relatives à la Croix-Rouge, aux soins infirmiers et au service social.

Membre ami de l'Association du Bon Secours à Genève, présidente nationale de l'Association suisse des infirmières, M"le Hentsch reçut en 1977 la Médaille Florence Nightingale, la plus haute distinction décernée par le CICR à une infirmière pour son dévouement exceptionnel à la cause du Mouvement international de la Croix-Rouge et du Croissant-Rouge.

Le Comité international de la Croix-Rouge présente à sa famille et à ses nombreux amis l'expression de sa sympathie la plus émue. 